\title{
ENTRE RECORTES, MONTAGENS E COSTURAS: o mundo imaginado é um mosaico ${ }^{1}$
}

\author{
Cecília Magalhães \\ (Universidade de Coimbra) \\ https://orcid.org/0000-0002-1943-0313
}

\section{RESUMO}

Meu principal objetivo nesse texto é discutir, tendo em vista os ensaios de Vilém Flusser sobre a reprodução das imagens técnicas e o futuro incerto da escrita, como os sistemas de reprodução linguística, em suas diferentes proposições, parecem apresentar um denominador comum, organizado em torno dos seus processos de materialização. Trato nesse caso desses processos não apenas consoante à intersecção de diferentes sistemas de linguagem, como é o caso do uso de estruturas visuais e pictográficas, dos caracteres verbais, da composição fílmica, entre outros. Trato também da peculiaridade compositiva desses rearranjos, organizados a partir de unidades estruturais em diferentes narrativas discursivas que também modificam-se pela própria evolução, reorganização e sobreposição de tais processos inscricionais. Para tanto, discuto a ideia desse complexo mosaico em confecção, consoante à ação criativa dos seus respectivos bricoleurs, ao fazer um paralelo entre as unidades estruturais dos códigos linguísticos com as unidades referentes aos códigos fílmicos, caso ilustrado aqui pela análise do vídeo educativo American Thrift como matéria-prima do videoclipe Cirrus. PALAVRAS-CHAVE: mundo imaginado, código, linguagem, processos inscricionais, mosaico.

1 Ensaio inicialmente desenvolvido no grupo de discussão Materialidades da Literatura I, parte integrante do programa doutoral Materialidades da Literatura, na Faculdade de Letras da Universidade de Coimbra. 


\title{
BETWEEN CUTOUTS, MOUNTS AND SEAMS: the imagined world is a mosaic
}

\begin{abstract}
My principal aim in this text is discussing, regarding Vilém Flusser's considerations about technical images reproduction and the uncertain future of writing, how linguistic systems in their different propositions present a common denominator connected to their materialisation processes. In this case, I examine these processes as an intersection of different linguistic systems, as visual and pictographic structures, verbal characters, film composition, etc. Further, I also explore the peculiarity of these arrangements in their structural units and their different discursive narratives, modified in their inscriptional processes' evolution, organisation and superposition. Therefore, I discuss the idea of this complex "in construction" mosaic, regarding their bricoleurs' creative acts, finding equivalence between the linguistic codes' structural units and the film codes' units, as I present here by the analysis of the educational video American Thrift as raw material of the videoclip Cirrus.
\end{abstract}

KEYWORDS: imagined world, code, language, inscriptional processes, mosaic.

\section{Considerações iniciais}

"Não mais vivenciamos, conhecemos e valorizamos o mundo graças a linhas escritas, mas agora graças a superfícies imaginadas" (FLUSSER, 2008, p. 11). Vilém Flusser abre categoricamente a primeira parte do seu ensaio, $O$ Universo das Imagens Técnicas, com esta afirmativa. $\mathrm{Na}$ perspectiva do filósofo, modificamos nossa percepção de mundo - antes significado pelo encadeamento linear dos fios textuais - em prol de um novo panorama marcado pela pretensiosa superficialidade das imagens. Entre as distintas formas de presença propostas na segmentação e inter-relação de diferentes tipos de linguagem não me interessa aqui discutir a 
predominância de um modo de textualização do mundo em detrimento de outro. Nesse sentido, o ponto nodal desse ensaio parte da busca do entendimento dos processos de codificação, textualização e, consequentemente, de organização de narrativas por meio das suas diferentes produções e reproduções. Como se dá a narrativa no espaço das imagens? Do contexto da produção escrita à produção imagética se mantém a mesma dinâmica de significação? Que tipo de materialidades constroem presença na organização complexa entre códigos, texto e narrativa?

Se contarmos que o mundo, sob a perspectiva do observador, pode ser interpretado e também ser ressignificado nos processos de produção textuais, esse ensaio presta-se em específico a demonstrar como tais processos interligam linguagens pelo modo como são praticadas, materializadas e mediadas. Trabalhamos partindo do olhar de Flusser e dos seus ensaios basilados pelos conceitos do mundo codificado (2007), da revolução das imagens técnicas (2008) e da morte da escrita (2011). Tratamos em um segundo momento desse ensaio da construção do código partindo das possibilidades visuais de codificação e reprodução em vídeo. Para tanto, Arlindo Machado apresenta coerente contribuição teórica em seu Pré-Cinemas \& Pós-Cinemas (2011). Por fim, apresentamos por meio da interligação entre os vídeos Cirrus (2013) e American Thrift (1962) algumas das possibilidades de reorganização narrativa e semântica pelos rearranjos de código e de texto e como elas permitem vislumbrar, em seu encadeamento, do pictórico à escrita, da escrita à imagem, um mesmo modus operandi - de rearranjo de elementos - nos processos de inscrição da linguagem no mundo.

\section{Projeções de um mundo imaginado: narrativa, código e texto}

O homem se coloca no mundo natural como um sujeito reagente à circunstância do seu entorno. Para tal intento, esse posicionamento não pressupõe apenas um determinado estatuto sensível e interpretativo. Tratamos aqui também das possibilidades de significação desse mundo por meio de diferentes modos de expressão e de representação. Nesse sentido entende-se que a circunstância - uma situação particular em que certos elementos são colocados em jogo em um determinado tempo e espaço - acionam tanto uma projeção subjetiva do olhar como também uma ação reativa das mãos na relação com o entorno. Aos moldes da Vênus de Willendorf, são tecidas assim, a partir dessas projeções, "a circunstância 
imaginada, a cena que representa a circunstância palpável. As mãos doravante, devidamente orientadas pelas imagens, agem sobre a circustância" (FLUSSER, 2008, p. 13).

Do olhar interpretativo às mãos habilidosas, vislumbramos nesse processo uma dinâmica de ordem narrativa: ela pode ter "caráter figurativo, comportando personagens que realizam ações, inscrita em coordenadas espaço-temporais" (GREIMAS; COURTÉS, 2008, p. 327), mas também pode representar "uma sucessão temporal de funções (no sentido de ações)" (PROPP citado em GREIMAS; COURTÉS, 2008, p. 327). Tal esquema narrativo implica por um lado o próprio ato do sujeito, in loco, de interpretação e de representação do mundo. Por outro, permite vislumbrar, enquanto resultado dessa representação do mundo, uma narrativa própria, figurada, do discurso gerado. Imbricam-se desse modo a narrativa produtora do sujeito assim como a resultante narrativa discursiva, ou seja, da sua inscrição criativa no mundo. Tratamos aqui da ação do homem no mundo e da projeção de um mundo "imaginado" (FLUSSER, 2007, 2008) $)^{2}$.

Se considerarmos o imbricamento de ambas narrativas como um processo de bricolage, ou seja, de um arranjo que produz sentido exatamente pelo modo de organização e de ressignificação das unidades expressivas em jogo, tal montagem busca, a partir de pequenas peças, plasmar forma. Nos moldes platônicos, Flusser (2007, p. 23) traduz "in-formar" como a ação de dar forma (morphé) à matéria amorfa (hylé) ${ }^{3}$. "In-formar" dá estofo, modela de um estado natural amorfo a outro. Nesse sentido, a produção de representações imaginadas do mundo, em sua capacidade in-formativa, depende dos modos de produção e de organização das peças em jogo. Fato é que tais peças nada mais são do que traços (mais ou menos complexos) que permitem, em sua inter-relação, traduzir e representar linguisticamente tais projeções do mundo imaginado.

A discursivização do mundo avança assim no processo que se inicia pelo poder tátil das mãos em conjunção com ele. Elas o ocupam, o

2 Flusser trata a fundo da definição de "imaginar" e a sua correlação com a ideia de "imagem" como código simbólico nas obras $O$ mundo codificado: por uma filosofia do design e da comunicação (2007) e $O$ universo das imagens técnicas (2008).

3 Essa correlação entre escrever, inscrever e sobrescrever em sua materialidade está nitidamente arraigada à ideia de in-formar, no sentido platônico de "dar forma”. Verificar também o texto Forma e Material (FLUSSER, 2007, p. 23-32). 
abstraem, o reproduzem: produzem novo sentido em superfície. Surgem esculturas, riscos e imagens. A inter-relação entre tais elementos figurativos complexifica-se consoante à necessidade de codificação do mundo de acordo com a complexificação do mundo imaginado. Tais sistemas de símbolos, ou códigos, têm o objetivo de contar histórias, mediar a comunicação entre os homens. Nesse sentido,

o homem é um animal "alienado" [...] e vê-se obrigado a criar símbolos e a ordená-los em códigos, caso queira transpor o abismo que há entre ele e o "mundo". Ele precisa "mediar" [...], precisa dar um sentido ao "mundo". (FLUSSER, 2007, p.130)

O homem grafa, organiza e costura as diferentes peças do código: como malha gráfica elas denotam sentido em seu arranjo topológico, independente da sua origem e do seu modo de reprodução. Do pictograma ao alfabeto fonético, da fotografia impressa ao vídeo, os elementos inerentes a determinado código organizam-se em uma determinada métrica bricoleur de produção de diálogo com o seu observador. Chamamos essa organização coerente de texto, "a totalidade de uma cadeia linguística, ilimitada em decorrência da produtividade do sistema" (HJELMSLEV citado em GREIMAS; COURTÉS, 2008, p. 503). Flusser descreve de modo muito visual essa organização ao definir o conceito de texto como

séries de conceitos, ábacos, colares. Os fios que ordenam os conceitos (por exemplo, a sintaxe, as regras matemáticas e lógicas) são frutos de convenção. Os textos representam cenas imaginadas assim como as cenas representam a circustância palpável. O universo mediado pelos textos, tal universo contável, é ordenado conforme os fios do texto. (2008, p. 14)

Se tomarmos como referência as organizações textuais de ordem verbal, elas sãos tecidos encadeados de caracteres, palavras, linhas e, claro, de espaços que geram contraste e legibilidade. $\mathrm{O}$ texto verbal tem uma dinâmica interessante: seu conteúdo se faz por uma estrutura que inter-relaciona caracteres e sons. A sua ordenação visual e cadenciamento rítmico são imprescindíveis, enquanto código fonético, para a pressuposição de um determinado significado que nos projeta novamente à subjetividade da imagem, do mundo imaginado. Do ponto de vista documental e de historicização da cultura, o código alfabético ganhou grande relevância ao permitir estabelecer e encadear significados de modo a produzir discursos complexos. Resultado disso é a evolução do pensamento científico e da produção literária. 
Fica claro que a evolução na estrutura dos códigos, dos seus modos de textualização e de se "in-formar" o mundo não necessariamente determinam o fim de um tipo de representação - escrita ou imagética ou qualquer que seja ${ }^{4}$ - em suas diversas possibilidades expressivas e técnicas. Como anteriormente ressaltamos, a representação do mundo pelo mundo "imaginado" se dá pela circunstância. Entre homem, circunstância e representação mantém-se, independente da sua tessitura sintático-semântica, a relação entre narrativa, código e texto. Para tanto, é importante compreender como esse jogo linguístico é transportado para a superfície do mundo.

Tratamos aqui dos modos de materialização e de imanência dessas estruturas linguísticas em sua prática, como elemento significante. Seguindo o pensamento etimológico de Flusser (2011, p. 25), se tomarmos como referência a origem latina "scribere" da palavra "escrever", ela pode ser traduzida como "riscar", assim como pode ser correlacionada diretamente com a ação de "inscrever". Escrever seria, nesse sentido, aos moldes da "inscrição", fazer "uma incisão sobre um objeto" (idem). Se "in-formar" nos permite construir sentido ao dar "forma" à matéria, o processo de inscrição segue nesse mesmo esteio: "inscrever" significa perfurar a superfície, gerar sulcos que constrastam com a extensa área plana da argila. Não é a toa que o contributo histórico-cultural das antigas civilizações jaz na perfuração da pedra. Com a modificação das circunstâncias, a complexificação do mundo "imaginado" e o consequente avanço (tanto no sentido evolutivo quanto em sua dinâmica de reprodução) na estrutura técnica dos códigos, os processos de escrita migram da inscrição para a sobrescrição: deposita-se a tinta, estampa-se, desenha-se, gera-se contraste na superfície. Como indica Flusser (2011, p. 36), os processos de sobrescrição modificaram a própria perspectiva do sujeito em sua prática:

pintar ao invés de cinzelar, para poder escrever com menos esforço e mais rápido. A rapidez no escrever é a diferença fundamental entre a inscrição e a sobrescrição. Pega-se um pincel ou uma pena [...], para se escrever no ímpeto do entusiasmo, com toda a leveza, como em um voo. Então vira-se a pena e escreve-se com sua ponta, para se escrever ainda mais rápido (FLUSSER, 2011, p. 36)

4 O ensaio A morte da escrita redigido por Flusser em 1989 e publicado posteriormente em 2011 trata da evolução da escrita enquanto processo historicizador da cultura. Um tanto quanto determinista, o autor vaticina o fim da escrita sobrepujada pelo domínio avassalador das imagens técnicas. 
Nas práticas de sobrescrição, o rápido movimento manuscrito da pena vislumbra já a eficiência do quebra-cabeças tipográfico (aos moldes do tipógrafo Johannes Gutemberg) que nos leva à automação do dedilhar da máquina de escrever, do computador. Partimos de uma relação da reprodução dos códigos que deixam de ser gravados para serem desenhados e finalmente montados, peça a peça, manchando a extensão do papel (ou da tela?). Se a estruturação do código em si já faz valer a ação do sujeito bricoleur, esse ato é mais uma vez reforçado na própria materialização do código - tecla a tecla - enquanto imagem técnica (FLUSSER, 2008, p. 59). Partindo dos avanços técnicos que permitem melhor abstrair e projetar o mundo imaginado, a própria dinâmica dos media - reconhecidas superfícies significantes - ganha novo status nos clicks que materializam informação.

No espelhamento do mundo em mundo imaginado, o resgate da visão de Demócrito nunca fez tanto sentido: a imagem técnica é, em si, um extenso mosaico (idem, p. 16) que se estrutura pela unidade minimal do ponto (pixel, retícula) $)^{5}$. Traçamos esse paralelo entre os processos de materialização do código e a sua forma de ordenação topológica de modo a tentar demonstrar como tal correlação nos permite visualizar um processo de produção de narrativas. De um modo ou de outro, tais processos denotam, pelo seu modo formal e prático de organização, os modos de uso e organização da linguagem. Na evolução dos processos de projeção do mundo imaginado, a superfície hoje se faz pelo ponto, o encadeamento dos pontos produz (pontualmente pelos clicks) elementos visuais, o encadeamento desses elementos produz códigos, que são entremeados de pontos que formam, em rede, novas imagens. Mundo imaginado 4.0?

\footnotetext{
5 Flusser avança no seu ensaio sobre as imagens técnicas tratando também da abstração e concretização das unidades minimais e das superfícies visíveis na equivalência com o código binário e suas propriedades de rasterização das imagens. Mesmo pincelando as características inerentes à materialidade da superfície de inscrição e sobrescrição dos códigos, não nos interessa neste ensaio aprofundar tal discussão levantada pelo autor, decerto essencial para compreender em todos os âmbitos as características inerentes às imagens técnicas. Focamos, de fato, em ilustrar a evolução dos modos de visualização da linguagem pelo código em seu caráter imagético e das suas possibilidades narrativas.
} 


\section{Gramática patchwork e a recodificação do mun- do imaginado}

Do traço pictórico às imagens técnicas, da inscrição na argila à sobrescrição na tela: a automatização nos processos de materialização dos códigos linguísticos ilustra não apenas como a circunstância modificou a projeção do mundo imaginado, mas como também influiu na sua execução e mediação. Nesse esteio, Flusser (2008) entende o fenômeno das imagens técnicas como um elogio à superficialidade. O termo "superfície" não trata aqui apenas da qualificação rasa ou zero-dimensional das

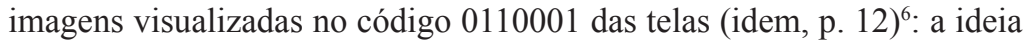
de superfície também condiz visualmente à extensão de uma determinada área. As dinâmicas possibilitadas pela espacialidade da imagem poderiam ser, nesse sentido, característica codificante? Como salientamos anteriormente, a organização do código em texto e narrativa acaba por depender do seu encadeamento topológico, ou seja, da definição de uma determinada disposição dos elementos de modo a instituir um determinado sentido. Nesse sentido, enquanto código, a imagem pode desdobrar-se em uma amplitude de possibilidades que remontam desde a sua prática pictórica. Historicamente os modos de presença do código-imagem foram revestidos com camadas e camadas de modificações nos âmbitos figurativo, matérico, cromático, rítmico e topológico, por meio da evolução das técnicas de produção e reprodução empregadas, assim como na sua própria presentificação como linguagem.

Se tomarmos como referência a imagem técnica partindo da sua evolução fílmica, ou seja, pela sua propriedade de reprodução de cenas em movimento, ela nada mais é que "um efeito de continuidade sobre uma sequência de imagens descontínuas" (MACHADO, 2011, p. 21). Arlindo Machado trata disso ao indicar o caráter ilusório (codificador) da produção de vídeos, sendo imprescindível "saber escolher a diferença mínima entre as imagens, capaz de simular um deslocamento (um movimento) sem que a descontinuidade estrutural seja notada" (idem). A prática

$6 \mathrm{O}$ autor faz um interessante comparativo entre as imagens tradicionais e as imagens técnicas no texto Abstrair. Ele discute que as primeiras partem de uma abstração da circunstância do mundo real na sua reprodução bidimensional, sobre a pedra, sobre a argila, sobre o papel. No segundo caso, as imagens técnicas se dão a ver da unidemensionalidade à zero-dimensionalidade, ou seja, do universo do código binário (FLUSSER, 2008, p. 11-21). 
de produção fílmica se faz, desse modo, pelo processo de recorte e montagem das imagens de acordo com as suas características e similaridades visuais. Busca-se assim gerar, na organização dos elementos, uma certa coerência narrativa que passa de forma incólume ao olhar do observador. Fazendo um paralelo curioso, Flusser (2011, p. 74) fala de um processo similar na organização do texto verbal em sua complexidade. $\mathrm{O}$ autor referencia a navalha de Ockham ao tratar da necessidade de "decupar" o texto de forma que ele possa atingir, pelos seus recortes e extrações, uma certa coerência formal. Mas se falamos de recortes verbo-textuais (parágrafos, frases, palavras, caracteres?), como as imagens estáticas em movimento sequencial podem ser nomeadas? Seguindo a terminologia fílmica, podemos inferir que o conceito de quadro (ou frame) nos serve como unidade fílmico-textual. Segundo a definição de Aumont e Marie, o quadro define "o que é imagem e o que está fora da imagem" (2006, p. 249). Ainda, tomando sua procedência no campo da arte, é "limite da superfície da imagem, ele desempenha um papel na organizacão formal da tela pintada ou da foto" (idem, p. 250).

Tomando o quadro como unidade e totalidade de sentido, vale compreendermos como ele se organiza de modo a produzir em sua sequencialidade uma determinada narrativa. Para tanto, o vídeo educativo American thrift: an expansive tribute to the "woman American" (1962) ${ }^{7}$ pode nos servir como matéria-bruta de análise. $\mathrm{O}$ vídeo trata, em termos "American Way of Life", do papel nuclear da mulher na estrutura familiar dos anos 60. Essa representação feminina, constituída principalmente na imagem maternal da dona de casa, é realçada por uma qualidade específica: sua responsabilidade no gerenciamento e na aquisição dos bens comuns à manutenção do núcleo familiar. É essa mulher a responsável por uma pretensa métrica "saudável" de consumo, prática aqui sugerida como base de representação do que é fazer parte da nação América:

Ours is a rich and variant land. We are prospering people. Wherever we live or earn our livelihood, we have bounties beyond those known to the people of any other day. And as responsible as anyone else of the care of these bounties is the woman in the American home. (CHEVROLET, American Thrift, 1962,1:05-1:30)

$7 \mathrm{O}$ vídeo American thrift: an expansive tribute to the "woman American" é de domínio público e encontra-se nos Arquivos Prelinger. Disponível em: https:// www.youtube.com/watch?v=jDfA0w3rNAU. Acesso em: 14 Jan. 2016. 
Vislumbramos de uma ponta à outra do vídeo uma narrativa que busca apresentar, em tom de voz compassado, uma métrica automatizada do cotidiano da família americana. Tal métrica se faz por narrativas geridas pela dinâmica de produção industrial da época e, consequentemente, da organização do mercado publicitário decorrente da criação dessa demanda. Reúne-se aqui a ideia de um cotidiano marcado por bens consumo que parecem, em sua aquisição, instaurar discursivamente um modelo para a próprio construto familiar e, em uma escala maior, dessa família-modelo como unidade componente da nação América. A sequência de cenas apresenta assim um panorama dessas vivências e dos respectivos hábitos de consumo da época que se faz - quadro a quadro - de acordo com uma composição específica dos elementos figurativos e plásticos em jogo. Em outros termos, esse modelo de núcleo familiar é ilustrado por meio das atividades comuns aos membros da casa, com especial destaque ao papel da mãe, responsável pela "delicada arte de se praticar a economia a partir de um olhar mais vasto" (CHEVROLET, American Thrift, 1962,11:17-11:25), servindo de mote para realçar as narrativas de consumo e de utilização de marcas. Crianças brincam, mulheres cuidam das atividades domésticas, o marido dirige e lê o jornal. As práticas diárias ganham vida nos pistões da indústria, nos estoques dos supermercados, nas ruas de comércio, no flerte com os novos produtos nas prateleiras. Nesses termos, a figuração da indústria enquanto motor da economia norte-americana se faz assim presente nos processos de seriação dos produtos apresentados: latas Campbell's pulam da fábrica para as mãos da dona-de-casa, madeira bruta torna-se souvenir, estoques são esvaziados conforme a crescente demanda de consumo. No convite feito à família de American Thrift, o ato de comprar é, sem dúvida, o ato cívico que rege, por vias econômicas, a nação.

Each of us wants what will suit us, and our own folks best. And so the producers of our free enterprise goods have to work to give us a wide variety of good old American choice. The things that are right for us as we see it. All brought to us by American competition in economy, providing us with the good life of plenties that we enjoy. (CHEVROLET, 1962, 18:25-19:03)

Se tomarmos essa narrativa apresentada e desvelarmos o caráter ilusório do movimento fílmico proposto encontraremos em seus quadros

8 Tradução da autora. 
a reprodução de outras métricas, como, por exemplo, nos modos de organização rítmica, topológica, cromática e formal das unidades componentes, quadro a quadro, de American Thrift. Mais do que figurativizar práticas de consumo enquanto mecanismo de organização do modelo familiar, tais unidades minimais instauram, em seu rearranjos de ordem semi-simbólica, padrões que parecem reforçar o discurso vigente de consumo, assim como também enredá-lo em subnarrativas de pertencimento social e de mais-valia tecnológica. Nesse sentido, decupamos American Thrift em 288 quadros $^{9}$ (verificar Quadro 1), sugerindo como referência exatamente a unidade do quadro a quadro, da transição de uma cena/ação sequencial à outra.

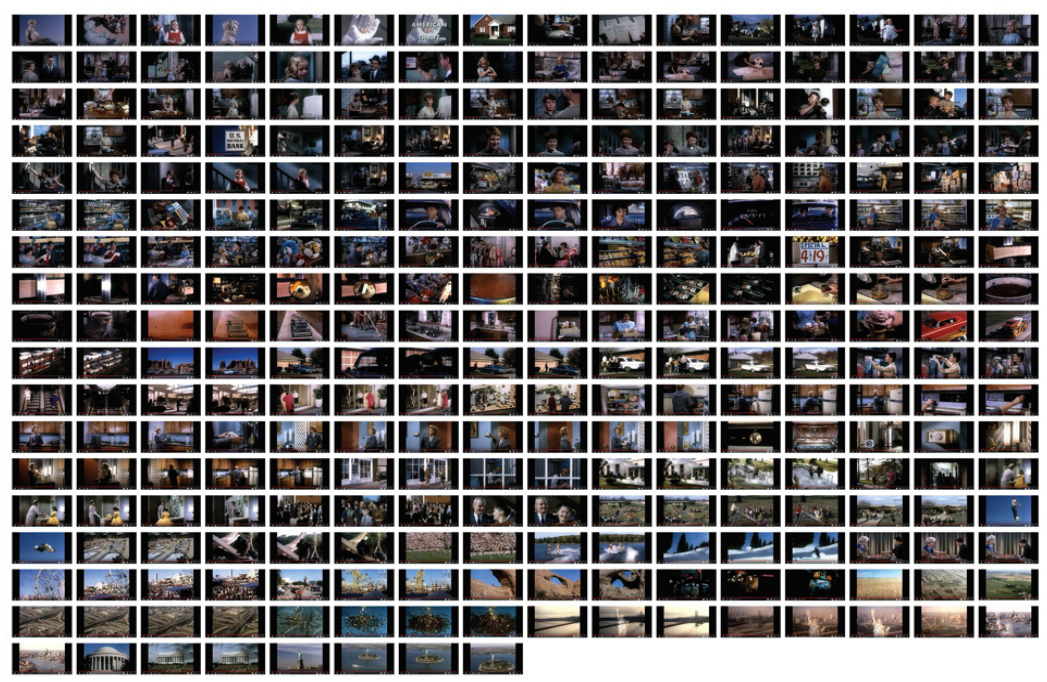

Quadro 1: American Thrift (1962) em 288 quadros, sequência de cortes da esquerda para direita, de cima para baixo.

Fonte: Elaborado pela autora.

9 O filme foi decupado tendo em vista apresentar as principais transições na construção das cenas e da narrativa do filme como um todo. Busca-se assim demonstrar, ao observar a inter-relação das unidades recortadas, a topologia entre os elementos quadro-a-quadro. 
A partir dessa decupagem conseguimos observar a repetição de determinados padrões no desenrolar do vídeo. O filme, como um todo, apresenta um movimento linear horizontalizado que se encarrega, da esquerda para a direita, em abrir claramente o panorama de vida apresentado. Esse movimento horizontalizado de câmera predomina nos quase vinte e seis minutos de vídeo, sendo complementado muitas vezes por outras dinâmicas rítmicas e de organização figurativa no quadro a quadro. Nesse caso observamos, por exemplo, o contraste entre quadros que centralizam e a estatizam as personagens, com especial destaque à figura materna, geralmente mesclados com outros quadros, os quais figuram contextos específicos de práticas de consumo e de interação com produtos etiquetados. A narrativa organiza-se, desse modo, pelo afastamento e pela aproximação da câmera que instituem, por um lado, a performance das personagens, e, por outro, mostram o contexto, o cenário onde ocorre a prática.

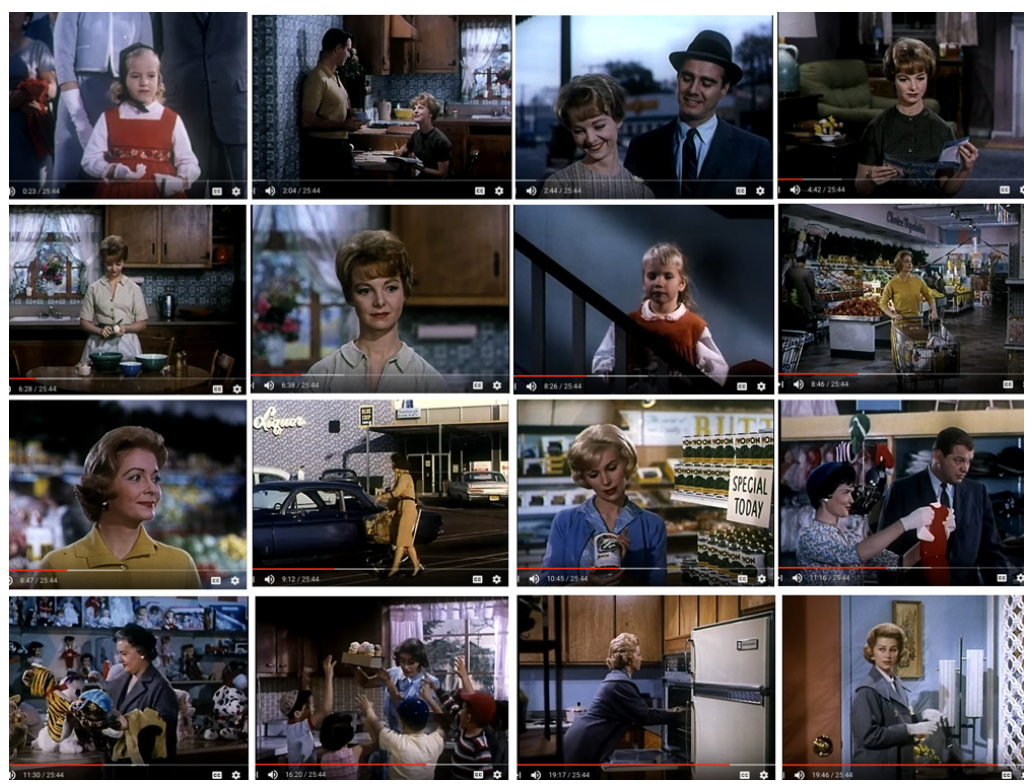

Quadro 2: American Thrift (1962), centralidade e aproximação das personagens inseridas no contexto de consumo.

Fonte: Elaborado pela autora. 
Outro ponto que pode aqui ser ressaltado, a título de curiosidade, sobre os modos de organização das unidades formais do vídeo, refere-se aos modos de invasão dos elementos em cena e a sua rítmica automatizada: tanto personagens como objetos e cenário são organizados no recorte diagonalizado dos quadros. Os efeitos de transição de uma cena à outra, seja na cartela cromática azul, cinza ou rosado, seja na organização figurativa da cena, também são reforçados nessas linhas. Elas se mantém como um grid: modifica-se a cena, mantém-se a organização formal dos quadros.
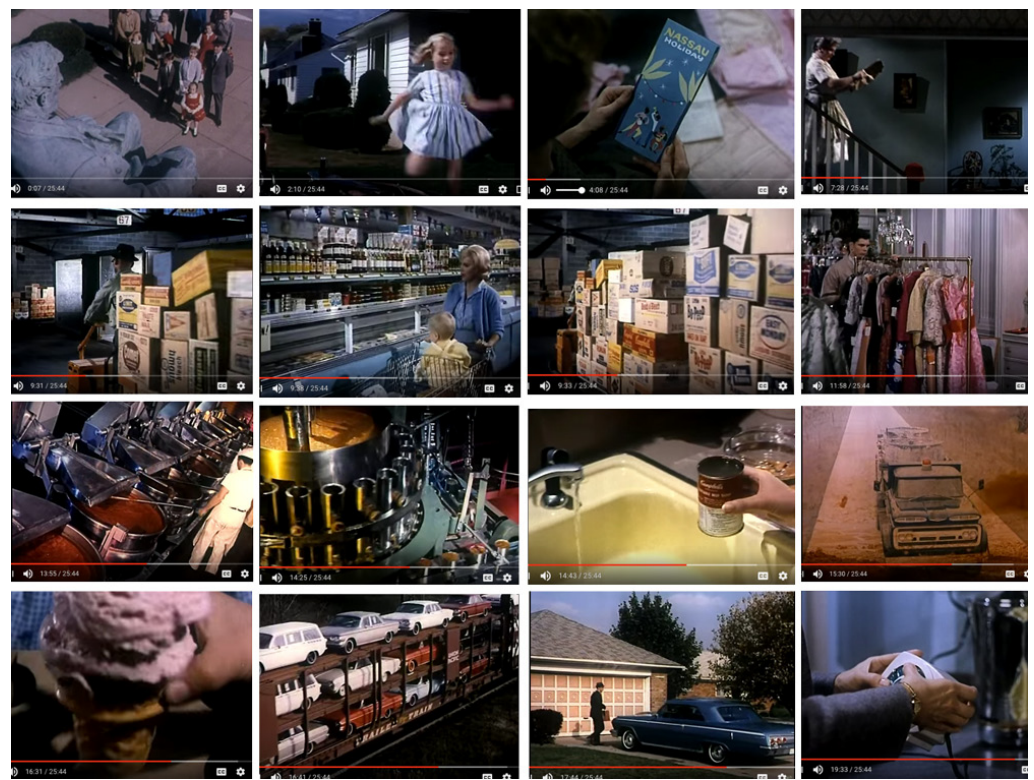

Quadro 3: American Thrift (1962), invasão de personagens e objetos em cena. Fonte: Elaborado pela autora.

O nosso intento aqui não é explorar ao máximo uma análise sobre os arranjos compositivos de American Thrift. Essa brevíssima observação sobre os dois pontos acima elencados nos serve, de fato, para sugerir como a produção do texto fílmico pode se fazer por meio de um código baseado nos recortes e na montagem sequencial (linear) dos quadros, assim como na disposição dos elementos inscritos quadro a quadro. 
A navalha de Ockham tem um papel preciso na organização do código fílmico. Porém, se tomarmos como princípio a organização sequencial dos quadros por um processo de corte/montagem, não seria possível também sugerir novas narrativas por diferentes modos de rearranjo desse código? Além disso, sugerir essas narrativas a partir dos modos expressivos dessas outras narrativas já estabelecidas? Imagina-se o vídeo como uma tapeçaria patchwork: a infinidade de possibilidades de composição depende, necessariamente, dos modos de organização e encadeamento dos seus elementos. Elementos os quais tinham anteriormente um outro sentido preestabelecido: eram tecido, peça de roupa, camisa. Nesses termos falamos aqui de recodificar ao reconfigurar diligentemente tais elementos em jogo. Partimos assim para uma nova gramática de projeção do mundo imaginado, mediado por outras perspectivas já imaginadas.

Fato é que a materialidade dessa gramática patchwork é passível de elaborar novas possibilidades narrativas ao reconfigurar o papel original da imagem-código. Arlindo Machado (2011, p. 102) nos traz o exemplo, nesse caso, das anamorfoses. Segundo o autor elas consistem "num deslocamento do ponto de vista a partir do qual uma imagem é visualizada, sem eliminar, entretanto, a posição anterior, decorrendo daí um desarranjo das relações perspectivas originais" (MACHADO, 2011, p. 102-103). Em outros termos, a metáfora da distorção da imagem nesse sentido funciona quase como uma sala de espelhos: uma mesma imagem que se transfigura ao mudar-se a perspectiva do olhar. O conceito de anamorfose no âmbito da sequência de quadros em movimento, ou seja, do seu deslocamento temporal, pode ser chamada de cronotópica: "materializado no espaço, o tempo se mostra como um efeito de superposição ou de percurso dos corpos no espaço" (idem, p. 105-106).

Os avanços técnicos possibilitados pelo uso dos dispositivos tecnológicos e a pretensa liberdade criativa proposta pela superfície da tela digital permitem, por meio da evolução de efeitos como a anamorfose cronotópica, um espaço de livre experimentação e de recodificação linguístico. De um modo ou de outro, tal liberdade mantém em pauta a competência bricoleur de rearranjo do código, do texto e da sua narrativa consoante à circunstância, seja ela mediada ou não. Nesse sentido, Cirrus (2013), vídeo experimental montado a partir de American Thrift para ritmar uma das composições eletrônicas do produtor musical Bonobo, é ótimo exemplo. 
O videomaker Cyriak usa American Thrift como uma textura de patchwork. Ele o desmonta, decupa, recorta e costura. O sonho americano, constituído na centralidade do feminino que rege as práticas de um consumo sistêmico (que se faz ritmado na automatização, na seriação e na exposição dos produtos quadro a quadro), acaba por se desvanecer na proposição de uma nova história. Movida pela rítmica instrumental de Bonobo, o vídeo é um encadeamento de ações pontuais, reordenadas e re-ritmadas de sujeitos, objetos e cenários que perdem, num paralelo com as anamorfoses, seu estatuto original: eles correspondem agora, em sua performance, à outra perspectiva da narrativa.

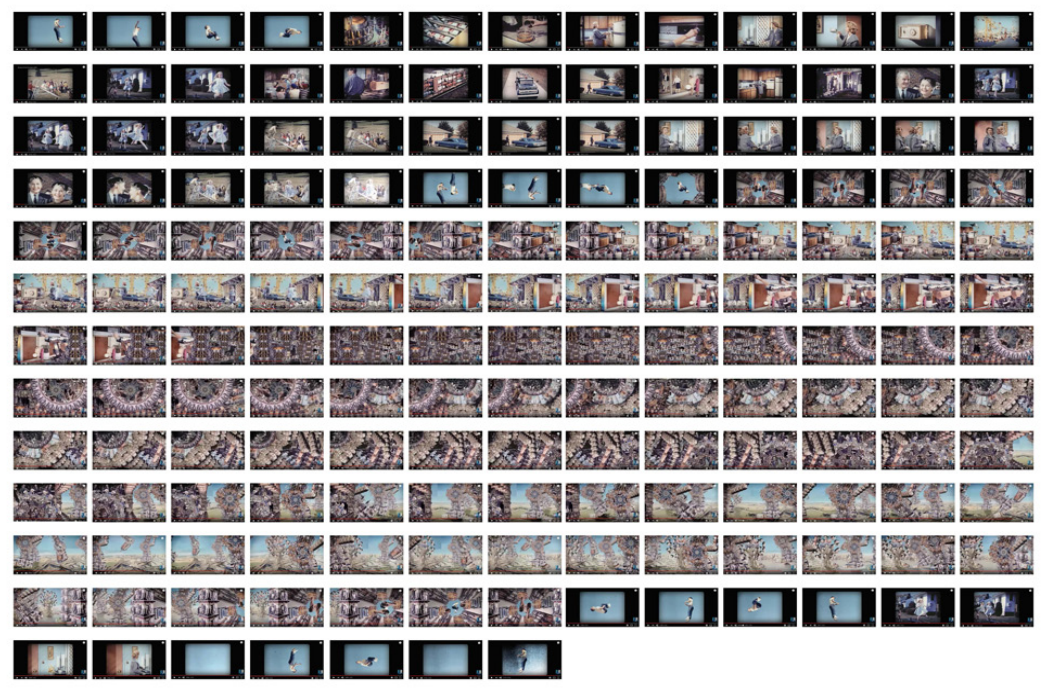

Quadro 4: Cirrus (2013), em 163 quadros, sequência de cortes da esquerda para direita, de cima para baixo.

Fonte: Elaborado pela autora.

Cyriak transforma American Thrift a partir de recortes de quadros específicos e do encadeamento de cenas originais (Verificar quadro 4). Tais recortes se transformam em componentes individuais que são aderidas, modeladas e formatadas de modo acessório e rítmico em novas figuratividades. Tais formas expressam, em sua totalidade, uma estética $S c i-F i$ que parece representar, na sequencialidade e estranha repetição 
de elementos, um cenário de ordem apocalíptica. Tal cenário nos remete em alguns momentos, por exemplo, aos gigantes invasores do clássico $A$ Guerra dos Mundos, de H. G. Wells (2000). Cyriak repete, automatiza e ritmiza as unidades figurativas e simbólicas de American Thrift ressaltando e ressignificando os traços expressivos do life style proposto em vídeo: uma América que dissolve-se entre humanos objetificados e objetos animados, alimentados por engrenagens que se modelam em figuras robóticas dominantes. Essas formas, em suas mais diversas formas possíveis, ocupam, em um novo ritmo, todo o espaço-tempo do vídeo.
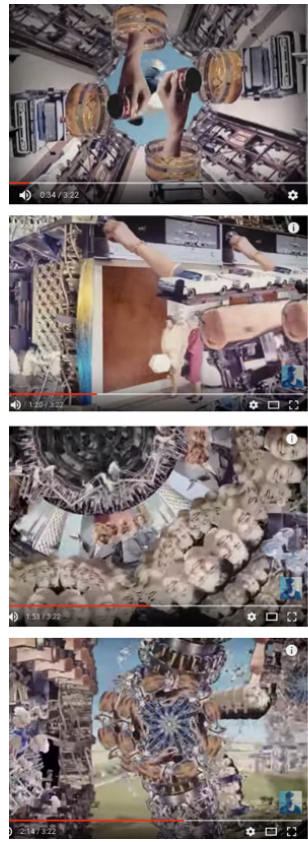
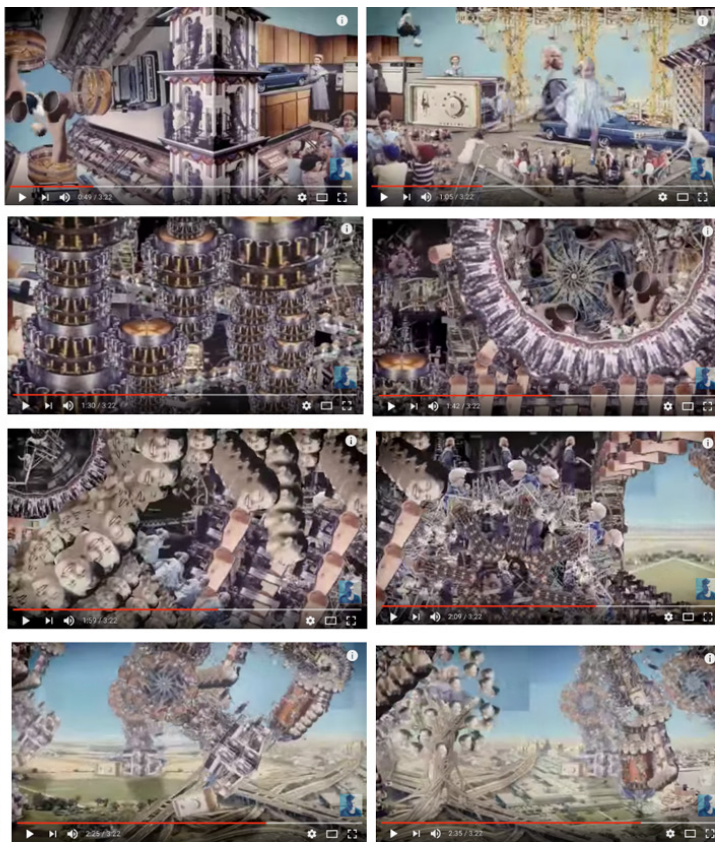
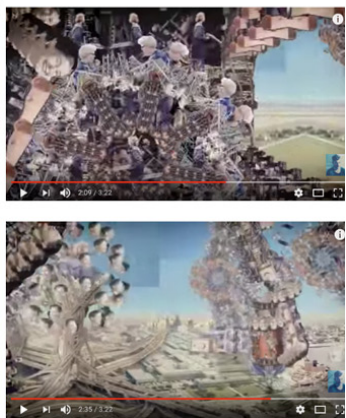

Quadro 5: Cirrus (2013), a maquinização e reconstrução das personagens de American Thrift

Fonte: Elaborado pela autora.

Mesmo ao transformar American Thrift em um extenso mosaico inumano, Cyriak deixa muito explícito de onde a narratividade de Cirrus nasce. Exemplo claro disso é o jogo que ele estabelece no início e no 
fim da sequência do videoclipe, ao fazer uma clara transição das formas originais do vídeo para a dinâmica das engrenagens em interação. Tudo se inicia com os loopings do garoto que recorta, em tom de brincadeira, o céu azulado e nos leva ao movimento seriado da fábrica. Na cena do quintal de casa, a menina corre e salta para se tornar não mais personagem: ela é elemento compositivo que se reproduz em série, assim como as demais figuras humanas do vídeo. É assim que os saltos do garoto surgem novamente, ao centro do vídeo, como convite ao mosaico de formas sequenciais.

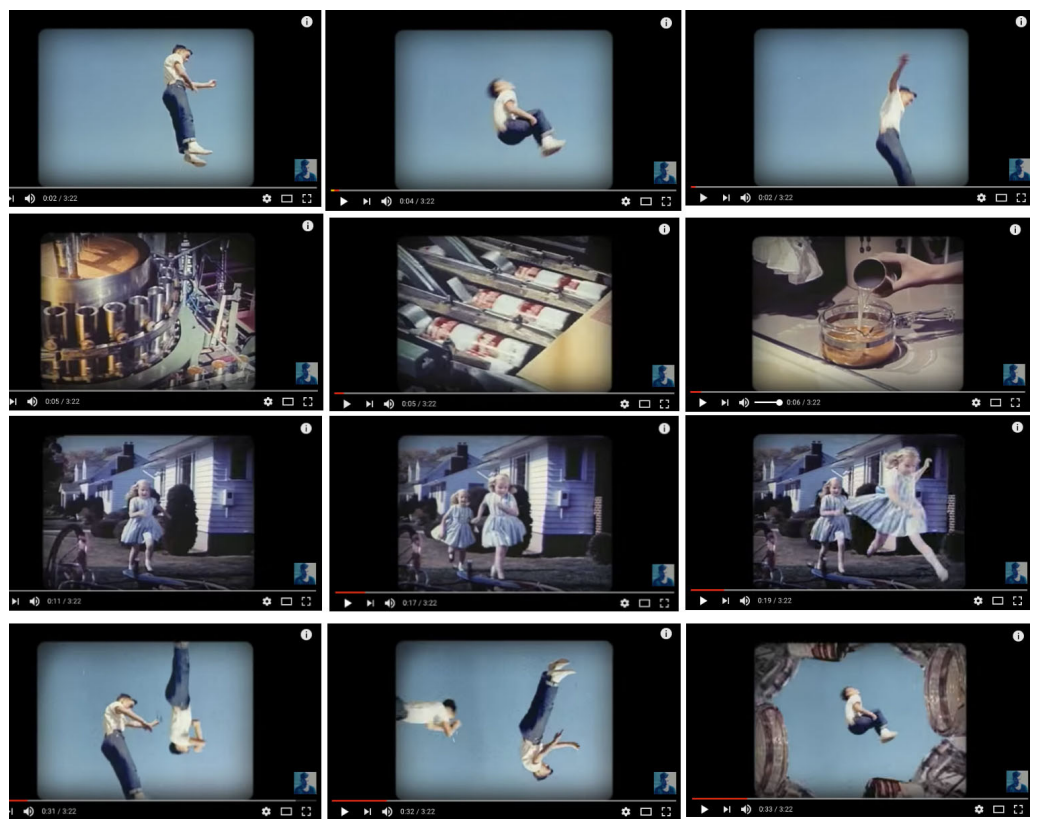

Quadro 6: Cirrus (2013), transição das unidades originais de American Thrift para o mosaico Cirrus.

Fonte: Elaborado pela autora.

Nesse sentido, mais do que propor uma nova narrativa, Cyriak busca também se opor à narrativa anterior por meio desse manejo das unidades do vídeo. O movimento da produção seriada de Campbell's se torna aqui mais do que uma engrenagem: é sujeito que caminha em sentido 
contrafluxo ao deslizar horizontal da câmera, base do movimento original de American Thrift. As narrativas de Cyriak são regidas exatamente pela inscrição, quase impositiva, desses recortes, em uma nova rítmica e topologia. Como código fílmico original eles são recodificados, desconstruindo assim a ode à crescente nação capitalista de 1960. Na dessemantização dos seus elementos e na sua ressignificação é assim também um novo arranjo textual. Ironicamente a família média americana alcança, por meio de Cyriak, seu papel absoluto enquanto produto de massa instituído.

\section{Considerações Finais}

O grande desafio de se projetar o mundo imaginado é, de fato, fazê-lo de modo que ele seja compreendido em sua complexidade textual. Para tanto, deve-se escolher, conforme circunstância, quais códigos exprimir, como encadeá-los em sua métrica de funcionamento, assim como definir a melhor superfície para desenhá-lo. Não bastasse isso, ainda é necessário estabelecer, a partir dessa massa amorfa, qual molde ela deve possuir para que possa, na sua narrativa de execução, ser uma narrativa in-formativa.

Esse ensaio buscou, nesse sentido, avançar sobre tais relações e, de certo modo, muito brevemente, reduzir o abismo entre linguagens pelas práticas e modos de produção do mundo imaginado. Por um lado, foi excelente exercício de aproximação com esse sujeito que projeta além. Por outro, transparece a necessidade de se avançar em outros terrenos mais profundos. Isso se dá tanto do ponto de vista teórico quanto na prática de integração de outros universos da linguagem aderentes à escrita. Essa sensação pessoal, de uma inteligibilidade que não se comporta apenas pelo texto verbal, se mostra deveras perceptível na fala de Flusser. O autor critica as imagens, vaticina à morte da escrita, determina historicamente grandes flancos intransponíveis entre os modos de presença da linguagem. Porém só consegue se fazer entender ao desenhar suas teorias de forma imagética: é por meio das palavras que o autor faz imaginar imagens sobre o papel das imagens. 


\section{REFERÊNCIAS BIBLIOGRÁFICAS}

AUMONT, Jacques; MARIE, Michel. Dicionário teórico e crítico de cinema. Tradução: ARAÚJO RIBEIRO, Eloísa. São Paulo: Papirus Editora, 2006.

CHEVROLET. American thrift: an expansive tribute to the "woman American", 1962. Disponível em: <http://www.dailymotion.com/video/x2p813f >. Acesso em: 14 Jan. 2016.

CYRIAK; BONOBO. Cirrus, 2013. Disponível em: <https://www.youtube.com/ watch? $\mathrm{v}=\mathrm{WF} 34 \mathrm{~N} 4 \mathrm{gJAKE}>$. Acesso em: 20 de dez. 2016.

FLUSSER, Vilém. A escrita - há futuro para a escrita? Tradução: DA COSTA, Murilo. São Paulo: Annablume, 2010.

. O universo das imagens técnicas: elogio à superficialidade. São Paulo: Annablume, 2008.

O mundo codificado: Por uma filosofia do design e da comunicação. Organização: CARDOSO, Rafael. Tradução: ABI-SÂMARA, Raquel. São Paulo: Cosac Naify, 2007.

GREIMAS, Algirdas J.; COURTÉS, Joseph. Dicionário de semiótica. Tradução: DIAS LIMA, Alceu et al. São Paulo: Editora Contexto, 2008.

MACHADO, Arlindo. Pré-cinemas e Pós-cinemas. São Paulo: Papirus Editora, 2011.

WELLS, Herbert George. A Guerra dos mundos. São Paulo: Nova Alexandria, 2000 .

Recebido em: 31/10/2018

Aceito em: 02/06/2019 